\title{
Calculation of temperature distribution and effective temperature in high burnup fuel of WWER-1000
}

\author{
Alexander Kudrov ${ }^{1 *}$, Arian Kuzmin ${ }^{1}$, and Denis Savitsky ${ }^{1}$ \\ ${ }^{1}$ National Research Tomsk Polytechnic University, 634050 Tomsk, Russia
}

\begin{abstract}
The problem of finding an effective temperature is highly important. This characteristic provides calculation of the power effect reactivity (PER), which defines safe and stable operation of nuclear reactor. The numerical experiment, which is considered on average and maximum heat load conditions, is put to find out changing of the effective temperature in the high burnup fuel of WWER-1000. In the course of the experiment mathematical statement of the problem is made, numerical solution of which is found with using the finite differences approximation of both control equations and border conditions. Also, the method of simple iteration is used for calculating temperature distributions, according to determination of the effective temperature. The linear approximation was obtained basing on effective and maximum temperatures depending on the burnup.
\end{abstract}

\section{Introduction}

One of the most important characteristics of a nuclear reactor is the power effect of reactivity (PER), which is defined with the effective temperature and actual amount of ${ }^{235} U$ in fuel. The effective temperature is an average temperature of a fuel pellet; it can be determined with the exact integral formula [1]:

$$
T_{e f f}=\frac{\int_{0}^{r_{T}} T_{T}(r) 2 \pi r d r}{\int_{0}^{r_{T}} 2 \pi r d r}
$$

where

$T_{T}(r)$-temperature distributions over the fuel pellet;

$T_{\max }$ - maximum temperatures on the axis of the fuel block;

$T_{c}$ - temperatures on the surface of the fuel block.

\footnotetext{
* Corresponding author: alex12kudrow@gmail.com
} 
Due to the Doppler effect, rising temperature leads to broadening of resonance levels of ${ }^{238} U$, which increases neutron absorption, thereby it reduces reactivity. PER has to be negative during the reactor company for providing safe and stable operation.

The rim-effect is a process of forming a thin layer around a periphery of the fuel pellet, it has high porosity and has increased heat release. The rim-layer is always associated with the high burnup fuel ( $\bar{B}>40 \mathrm{MWd} / \mathrm{kgU}$ ). According WWER-1000 design, maximum burnup, that can be reached, is $70 \mathrm{MWd} / \mathrm{kgU}$. It means that calculations of the effective temperature must be provided with considering of the rim-effect.

\section{Mathematical formulation of the problem}

Calculation of the effective temperature requires the known temperature distribution, which can be found from following equations:

$$
\begin{aligned}
& \frac{1}{r} \frac{d}{d r}\left(\lambda_{0}\left(T_{1}\right) r \frac{d T_{1}(r)}{d r}\right)+q_{v}(r)=0, \\
& \frac{1}{r} \frac{d}{d r}\left(\lambda_{r i m}\left(T_{2}\right) r \frac{d T_{2}(r)}{d r}\right)+q_{v}(r)=0,
\end{aligned}
$$

where

$\lambda_{0}\left(T_{1}\right)$ is the thermal conductivity of the inner area, $W /\left(m \cdot{ }^{\circ} \mathrm{C}\right)$;

$T_{1}(r)$ is the temperature distribution in the inner area, ${ }^{\circ} C$;

$q_{v}(r)$ is radial distribution of heat release in the fuel pellet, $W / \mathrm{m}^{3}$;

$T_{2}(r)$ is the temperature distribution in the rim-layer, ${ }^{\circ} C$;

$\lambda_{\text {rim }}\left(T_{\text {rim }}\right)$ is the thermal conductivity of the rim-layer, $W /\left(m \cdot{ }^{\circ} \mathrm{C}\right)$.

Boundary conditions:

$$
\begin{gathered}
r=0,\left.\frac{d T_{1}(r)}{d r}\right|_{r=0}=0 ; \\
r=R_{1}, T_{1}\left(r=R_{1}\right)=T_{2}\left(r=R_{1}\right) ; \\
r=R_{1},-\left.\lambda_{1}\left(T_{1}\right) \frac{d T_{1}}{d r}\right|_{r=R_{1}}=-\left.\lambda_{2}\left(T_{2}\right) \frac{d T_{2}}{d r}\right|_{r=R_{1}} ; \\
r=r_{p}, T_{2}\left(r=r_{p}\right)=T_{c},
\end{gathered}
$$

where

$R_{1}$ is the radius of inner area, $\mathrm{mm}$;

$T_{c}$ is temperature on a the surface of the fuel pellet, ${ }^{\circ} \mathrm{C}$.

Due to a non-linearity of (2) and (3), the analytical solution cannot be found, therefore the numerical method of finite differences and method of the simple iteration was used. 


\section{Influence of radiation on properties of the fuel rod}

Degradation of thermal conductivity may be expressed with following formulas [2]:

$$
\begin{gathered}
\lambda_{95}=\left[\left(0.1148+3.0864 \cdot 10^{-3} \bar{B}\right)+2.475 \cdot 10^{-4}\left(1-2.95 \cdot 10^{-3} \bar{B}\right) T\right]^{-1} \\
+0.0132 \exp \left(1.88 \cdot 10^{-3} T\right)
\end{gathered}
$$

where

$\bar{B}$ is an average burnup in the fuel pellet, $M W d / \mathrm{kgU}$;

$T$ is temperature, ${ }^{\circ} \mathrm{C}$.

$$
\begin{gathered}
\lambda_{0}=\lambda_{95} /\left[1-\left(2.58-0.58 \cdot 10^{-3} T\right) \cdot 0.05\right] ; \\
\lambda_{\text {rim }}=\lambda_{0}\left\{1-P^{2 / 3}\left[1-1 /\left(1+P^{1 / 3}\left(\lambda_{0} / \lambda_{X e}-1\right)\right)\right]\right\},
\end{gathered}
$$

where

$P=N \pi d^{3} / 6$ is porosity of the rim region ( $d$-diameter of the pore, $N$ - volume density of pores, $\left.\mathrm{m}^{-3}\right)$;

$\lambda_{X e}$ is thermal conductivity of gas in the pores, $W /\left(m \cdot{ }^{\circ} \mathrm{C}\right)$.

The expression (8) describes degradation of the thermal conductivity due to microstructural changes caused by the radiation effect, (9) takes account of accumulation of solid fission products; (10) is thermal conductivity of rim region.

The high burnup fuel rod experiences swelling, which causes absence of a central hole in pellet and gas gap between the pellet and the fuel cladding. Thickness of the rim-layer can be calculated with the following formula [2].

$$
\delta_{R I M}=-32.5+2.34 \cdot \bar{B}
$$

The radial distribution of the heat release is represented on figure 1 [3]. It has the same form as the radial distribution of ${ }^{239} \mathrm{Pu}$ in the fuel pellet [4,5], and does not depend on burnup.

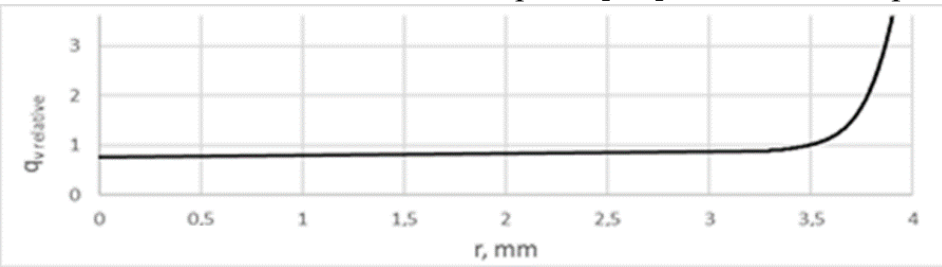

Fig. 1. Radial distribution of relative heat release.

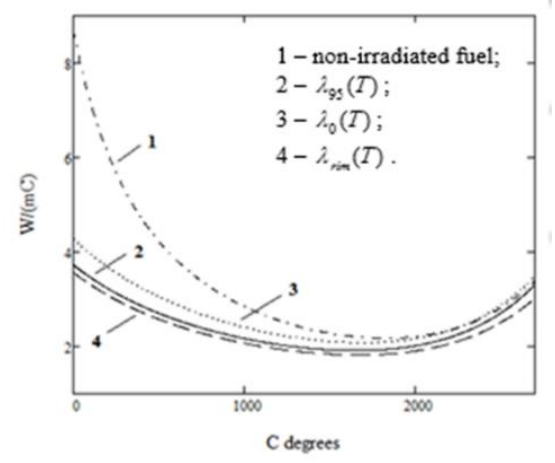

Fig. 2. Dependence of thermal conductivity on temperature. 


\section{Results of calculations}

Temperature distributions were found in interval of burnups from $40 \mathrm{MWd} / \mathrm{kgU}$ to $100 \mathrm{MWd} / \mathrm{kgU}$. Dependence of maximum and effective temperatures is represented in the Table 1.

Table 1. Maximum and effective temperatures on different burnup levels.

\begin{tabular}{|c|c|c|c|c|c|c|c|}
\hline \multicolumn{7}{|c|}{ Average heat load } \\
\hline Burnup, $M W d / \mathrm{kgU}$ & 40 & 50 & 60 & 70 & 80 & 90 & 100 \\
\hline$T_{\max },{ }^{\circ} \mathrm{C}$ & 1379.5 & 1455.0 & 1527.1 & 1595.6 & 1660.6 & 1722.2 & 1798.7 \\
\hline$T_{\text {eff, }}{ }^{\circ} \mathrm{C}$ & 833.6 & 872.4 & 910.2 & 946.9 & 982.7 & 1017.4 & 1066.4 \\
\hline
\end{tabular}

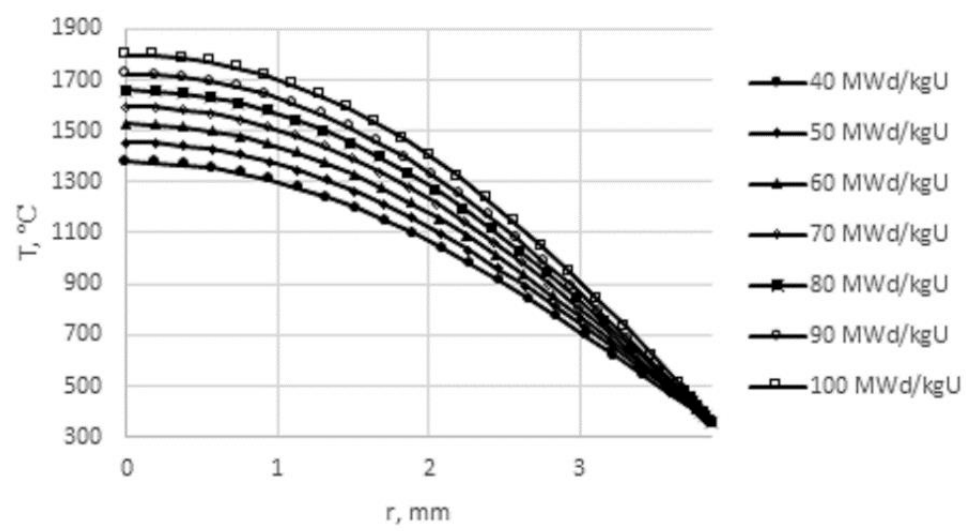

Fig. 3. Temperature distributions in the fuel pellet on different burnup levels.

Dependence of effective and maximum temperatures from burnup was approximated by linear functions. For average heat load those functions look like:

$$
\begin{aligned}
T_{\text {eff }} & =3.7889 \cdot \bar{B}+681.9 ; \\
T_{\max } & =6.8767 \cdot \bar{B}+1109.9 .
\end{aligned}
$$

These expressions have error less than $1 \%$.

\section{References}

1. G. G. Bartholomew, G. A. Bat', V. D. Bajbakov, M. S. Alhutov, Fundamentals of the Theory and Methods for Calculating Nuclear Power Reactors (YULAND Publ., Yekaterinburg, 2016)

2. B. H. Lee, Y. H. Koo, D. S. Sohn, JNST 38, 45 (2010)

3. S. U. Kurchatov, V. V. Likhansky, A. A. Sorokin, O. V. Khoruzhy, Atom. Energy 92, 317 (202)

4. K. Lassmann, C. O'Carroll, J. van de Laar, C. T. Walker, J. Nucl. Mater. 208, 223 (1994)

5. L. D. Palmer, K. Hesketh, P. A. Jackson, IAEA 321 (1982) 